\title{
COMMUNITY-BASED SERVICE FOR THE FRAIL ELDERLY IN CHINA
}

\author{
Joe Leung \\ \& \\ Y. C. Wong
}

Department of Social Work and Social Administration, The University of Hong Kong, Pokfulam Road, HONG KONG Fax: (852) 28587604

E-Mail: Hrnwlcb@hkucc.hku.hk 


\title{
COMMUNITY-BASED SERVICE FOR THE FRAIL ELDERLY IN CHINA
}

\author{
Joe Leung \& Y. C. Wong
}

\begin{abstract}
This is a study of community-based social services for the frail elderly in China. As China is turning into an ageing society and the capacity of the family support for the frail elderly is rapidly declining, there is an urgent need to develop formal social services to support elderly persons to continue to live in their community. This paper provides a general background on the structure of the emergent community services. With the use of an example of a city in China, the operation of the community services for the elderly people would be illustrated. Finally, the strengths and limitations of community services would be discussed.
\end{abstract}

Key words:

Community services, frail elderly, family support, homes for the aged.

Information about the authors:

Dr. J. Leung is associate professor and Mr. Y. C. Wong is lecturer in the Department of Social Work and Social Administration, The University of Hong Kong. Publications of Dr. Leung focus on social welfare in China. Mr. Wong supervises Hong Kong social work students in fieldwork placements in China.

\section{Correspondence Address:}

Department of Social Work and Social Administration, The University of Hong Kong

Pokfulam Road

Fax: (852) 28587604

E-Mail: hrnwlcb@hkucc.hku.hk 


\section{COMMUNITY-BASED SERVICE FOR THE FRAIL ELDERLY IN CHINA}

\section{Introduction}

China is turning into an aging society. For centuries, it has been a cherished Chinese tradition for the elderly people to be supported by their offspring; and formal social services for the aged were often regarded as not necessary. With the introduction of economic reforms beginning in 1978, family capacity and willingness to provide care for the elderly are rapidly eroding. Inevitably, the government is encouraging the development of neighbourhood-based social services to take care of the impending financial and practical needs of the frail elderly people. This paper describes the structure and operation of these community-based welfare services. With the case study of a neighbourhood in Guangzhou city, the potentials and constraints of community services would be explored. (The case study is part of the research project of the authors to investigate welfare reforms in Guangzhou city.)

\section{China as an Ageing Society}

One of the consequences of the draconian population control policy in China is the rapid increase in the proportion of the elderly population. In 1995, China had 81 million elderly people, aged 65 and over, representing 6.7 per cent of the national population. The proportion is much higher in cities such as Shanghai (12.2 per cent) and Beijing (8.8 per cent). From 1991 to 1995, the elderly population increased at an average annual rate of 4.9 per cent. The increase rate is four times the average annual population growth rates, and is 2.25 times higher than the growth rate five years ago (Beijing Review, 10-16 March 1997:23). Demographic projections show that the elderly population will reach 7 per cent by the year 2000, and further to 11.4 per cent by the year 2020 (State Statistical Bureau, 1997:490, 1998:107). What worries the Chinese government most is the speed of the increase in the proportion of the elderly 
people. It took only 20 years for China's elderly population to increase from 5 per cent to 7 per cent of the national population. In the early days of other developed countries, similar increases took at least 50 years. Being one of the fastest ageing societies in the world, China has to shoulder all the burden found in the developed countries with the level of the economy of a developing country.

Among the elderly population in 1995, 8.4 per cent were the old-old (over 80 years old). Among the elderly aged between 60 and 64, the sex ratio is 100 women to 104.6 men, but the ratio drops to 100 women to 55.8 men for those aged over 80 years old (State Statistical Bureau, 1995:62). A national survey in 1994 showed that 7.8 per cent of the elderly aged over 60 years old, or 9 million people had to depend on others to take care of them. As expected, only 3.4 per cent of those aged between 60 and 69 were unable to take care of their daily needs themselves while the percentage increased to 28.4 per cent for those aged 80 or over (State Statistical Bureau, 1995:66). Another survey also showed that some 25 per cent of the elderly population aged over 60 years old, or 25-27 million people, were in poor health conditions (Shi and Zhu, 1998:35). The survey by the China Research Centre on Ageing also found that some 93-98 per cent of the elderly people in fact could take care of themselves in dressing, feeding, bathing and toileting. For those who could not take care of themselves, their main caregivers were their spouses and adult children. Care provided by the domestic helpers, volunteers and social services were minimal. In other words, the majority of elderly in China are still living with and cared by their children. In the 1990 census, some 70 per cent of elderly lived with their children (82.2 per cent in 1987). Still, 11.3 per cent of the urban elderly and 13 per cent of the rural elderly lived alone (China Research Centre on Aging, 1994:9). In Shanghai, surveys showed that seven per cent of the elderly population could not take care of their daily need themselves, and 2.6 
per cent were bedridden (China Civil Affairs, 7, 1997:23).

As a developing country, both the pension system and formal social services for the elderly are largely inadequate. In a national survey in 1994 on major sources of income for the elderly, 31.8 per cent had a comparatively stable source of income support from employment (17.1 per cent) and pensions (14.7 per cent). The remaining were supported mainly by their children and relatives (Beijing Review, 10-16 March 1997:23). For those over 80 years old, some 86.2 per cent had to rely on their families for economic support, and 28.4 per cent of them were unable to take care of their daily needs themselves (State Statistical Bureau, 1995:66). Furthermore, gender differences in the receipt of pensions and employment is significant. Women have to rely more than men on family for economic support (Leung, 1997).

All along, the government has been convinced that the family should have the primary responsibility for the care of the elderly people. The Criminal Law (1979), Article 183, makes it an offense, punishable by a sentence of not more than five years' criminal detention, for adult children to refuse to perform their proper duty to support an aged family member. The welfare role of the adult children, including adopted children to support their parents as well as parents-in-law was reiterated in the revised Marriage Law (1980), the Inheritance Law (1985), and the Law on the Protection of the Rights and Interests of the Elderly (1996).

However, the capacity of the family to provide care for aged members is rapidly eroding. Now, 76 per cent of families are nuclear families (families with one to four persons); the average household size in 1997 was 3.6 persons (2.8 persons in Shanghai), down from 4.4 persons in 1982. Smaller family size means there are fewer potential caregivers. Furthermore, the number of divorces granted in 1997 reached 1.2 million, which is three times the number in 1981 (State Statistical Bureau, 1998:109, 
800).

Today's elderly people were born in or before the 1930s, and married in the 1950s, the period when there was a baby boom. Therefore, they, on average, have three to four children (3.5 in cities and 3.7 in villages) to share the responsibility of care (China Research Centre on Aging, 1994:8). But when their children who married and gave birth to children in the mid-1970s and the early 1980s turn old early in the next century, they most likely will have only one child to look after them. This is called the phenomenon of " $4-2-1$ ”: that is the responsibility of caring the two parents and the four grandparents will rest on the sole grown up child.

\section{Welfare Services for the Elderly}

Under the centrally-planned economy modeled after the Soviet Union, the social welfare system was employment-centred. Each work unit functioned as a self-sufficient "welfare society" within which an individual received employment and income protection, and enjoyed heavily subsidized benefits and services such as housing, food, education, recreation, child care, and social security benefits for sickness, maternity, work injury, invalidity and death, and old age (Leung, 1994a; Leung and Nann, 1995). For the few people outside the work units, the state would provide a remedial welfare programme for the 'three nos': those with no family, no source of income, and no working ability. The domination of the work unit-centred welfare had rendered social services organized by non-governmental charities and government departments unnecessary. Under the market-oriented economic reforms, work unit commitments towards welfare is rapidly eroding, and there is a rising needs for the development of non-employment-based welfare.

Despite the fact that only a small proportion of elderly people in China are eligible for pensions, expenditures on welfare in work units jumped from 7.8 billion 
yuan (1 US\$ is equal to 8.3 yuan) in 1978 (13.7 per cent of total wages) to 93.8 billion yuan in 1990 (31.8 per cent of total wages), and to 304.4 billion yuan in 1997 (30.4 per cent of total wages). In 1997, money spent on pensions and medical care of retirees accounted for 67.2 per cent of total welfare expenses in state-owned enterprises. The number of retirees receiving pensions grew from 3.1 million in 1978 to 23 million in 1990, and to 33.5 million in 1997. The ratio of employees to retirees decreased from 30: 1 to 6.1: 1 in 1990, and to 4.4: 1 in 1997 (State Statistical Bureau, 1998:797-98). Impending problems of the current pension system include its narrow coverage, high and uneven contribution from employers, the lack of sufficient accumulation to cope with future liabilities, and poor fund management (World Bank, 1997; Leung, 1998).

Currently, social welfare services consist of mainly welfare institutions. They provide residential care for the 'three nos'. They include the mentally ill, the mentally handicapped, orphans and the childless elderly. In 1997, they provided a total of 1,031,022 residential places. Some 90 per cent of them are homes for the aged. In addition, some 82 per cent of these places were provided by the neighbourhood governments (street offices in the cities and township governments in the rural areas), and the rest were by Civil Affairs Departments (State Statistical Bureau, 1998:792). With an occupancy rate of only 76 per cent, these homes were largely underutilized. This phenomenon reflects the traditional reluctance of the elderly people in China to live in institutions. Since 1983 these institutions have been opened to people who can afford to pay the market fees.

With an elderly population (over 60 years old) of 120 million in 1997, the institutionalization rate of elderly people is extremely low, representing about 0.56 per cent. According to a survey in Beijing, homes for the aged provided a total of 
10,946 beds, but only 63.9 per cent of these beds were in used, accommodating 7,000 people. The number of elderly people in institutional care accounted for 0.42 per cent of the elderly population (1.7 million people) (Beijing Review, 8-14 February 1999:21). In Shanghai, the rate is only 0.3 per cent (China Civil Affairs, 7, 1997:23).

Besides residential care, other forms of formal services for the frail elderly such as nursing homes, care and attention homes, home help, and day care centres are largely non-existent. Furthermore, only those 'three nos' elderly people, those with no family, no working ability and no source of income can be admitted free of charge to homes for the aged operated by government and neighbourhood organizations.

Finally, there is hardly any independent non-governmental organizations providing social welfare services in China. There are a handful of international relief organizations, such as Oxfam, World Visions, and Hong Kong-based welfare organizations operating inside China, but their services are more restricted to rural relief and educational programmes. In some large cities, private for-profit homes for the aged are found to fill the need of the elderly care market.

\section{The Development of Community Services}

As a new source of welfare, community-based welfare services for vulnerable populations in cities have been enthusiastically promoted by the government in the 1990s. In China, an urban neighbourhood of about 50,000 residents is administered by a street office, an extension of the district people's government. The street office is responsible for the provision of a variety of community services including both public and social services. Public services for general residents include fire and crime patrols, environmental management, sanitation improvement, marriage registration, household registration, family planning, family and neighbourhood mediation, household repairs, bicycle parking, and recreational and cultural activities. Welfare services include 
supervision of delinquents, nurseries, recreational and cultural activities, job placements for the unemployed, homes the aged, day care centres for the disabled and the elderly, shelter workshops for the disabled and the mentally ill. Recent emphasis is on the development of volunteer services. Community services are regarded as an emergent and vital source of personal social services, particularly for the vulnerable populations, such as the frail and single elderly, orphans, the physically and mentally disabled, the chronically ill, the ex-criminals, the ex-servicemen, the unemployed, low-income families, and youth at risk.

Under the supervision of each street office are a number of residents' committees. Each committee, governing an average of 500-700 households, is responsible to assist the street office in implementing government policies and operating community service programmes. Committee members, including the chairman and vice-chairman are elected by local residents. Because residents' committees are closely supervised by street offices, they are in fact semi-governmental organizations.

In 1996, there was a total of 3,400 community service centres at the street office level, 440,000 community service stations at the residents' committee level, 6,300 homes for the aged, 160,000 service units for the aged (day care centres, marriage matching service, activity centres), 140,000 service units for the ex-servicemen, and 37,000 service units for the disabled. To operate these community service programmes, some 580,000 full-time cadres and 600,000 part-time cadres as well as 5.5 million volunteers are involved (Shi and Zhu, 1998:48).

With limited financial support from city governments, each neighbourhood has to rely on its own efforts to develop public and welfare services. In the case of Guangzhou city, city government allocation for community service only accounts for 
30 per cent of the total expenses. Profits derived from commercial enterprises (factories, restaurants and guest houses) and fee-charging public and welfare services managed by the street offices are used to finance overall operations. The principle, in the Chinese sayings, is 'to use profit-making service to support service that is free of charge.' Another major source of funds to finance community services comes from the allocation from the city welfare lottery fund (China has introduced welfare lotteries to finance welfare programmes since 1987). Furthermore, community services can receive preferential treatment from the city government in terms of taxation and credits. As such, it is exceedingly difficult to separate the welfare and profit-making commercial functions of community services. Because the provision of welfare services is largely dependent on the ability of the street office to develop a profitable local economy, the quality and quantity of the welfare services provided can vary substantially from neighbourhood to neighbourhood. Oftentimes, street offices in commercial districts and city centres tend to have much higher revenues. In some street offices, charity funds for welfare are established with revenue from public donations, profits in welfare enterprises and street office allocations. In general, community services are both informal and loosely-structured with the quality of services not standardized.

The quality of community services is also plagued by the poor staff quality of neighbourhood cadres. Particularly in residents' committees, the majority of the cadres are retirees and redundant workers laid off from ailing state enterprises. Social work educators in China have advocated the urgent need to turn neighbourhood cadres into professional social workers (Leung, 1994b). In Shanghai, the city government has made requests to universities to train professional social workers as community workers. 


\section{Services for the Frail Elderly}

Here are some of the typical services provided by the street office to the homebound elderly people.

Homes for the Aged

Homes for the aged operated by the street offices can provide care to the elderly people in need. These homes are usually small in size, and some may just have several residents only. Only those who are defined as "three nos" can be admitted to the homes free of charge. In both Shanghai and Guangzhou, some 20 per cent of the places in the homes operated by the street offices are for the 'three nos.'

\section{Social Assistance}

To extend the commitment, the government introduced in 1990s a community-based social assistance programme. The programme is financed by the city governments, but the administration is community-based. Street office cadres are responsible for carrying out investigations, delivering the benefits and reviewing the situation of the recipients periodically. Based on the principle of deterrence, the provision is rendered so unpleasant and harsh as to deter all save the most desperate. To facilitate 'public monitoring' of the situation of the recipients, the names of the recipients and the amount of benefits received would be publicized in the neighborhood bulletin boards. Among the 36 cases receiving assistance in one of the Street Offices in Guangzhou, 14 cases were the "three nos", with an average age 76 years (Leung, 1999a).

\section{Care Groups}

For those elderly people live alone and not in institutional care, the street office can make arrangements to establish a care group for each elderly person in need. The care group is formed with cadres and volunteers. The group would provide the basic 
need of home help, meal delivery, escort to consult doctors, clothes washing and house cleaning (Leung, 1990).

Family Mediation

According to the Law on Protection of the Rights and Interests of the Elderly, neighbourhood cadres are responsible to ensure that adult children would carry out their filial obligations to provide care for their elderly parents. Whenever there is a dispute over the filial responsibility, neighbourhood cadres would provide mediation between family members. If mediation fails, they can bring the case directly to the People’s Court. In short, neighborhood cadres have the responsibility to enforce and monitor family care obligations, and to ensure that elderly persons in needs are to be taken care of by their children.

Home beds

Doctors of some hospitals can provide consultation visits to patients without the need of hospitalization. In China, the arrangement is called "home bed". Wages of medical doctors are poor, and 80 per cent of the expenditures of hospitals go to drugs and medicine.

Finally, community-based welfare services are provided by a mixed of neighbourhood cadres and volunteers. Due to soaring layoffs by state-owned enterprise to improve efficiency, community services have become a popular channel providing temporary jobs for the unemployed (Leung, 1996).

A study on the need of community services among the elderly in Tianjin showed that 94 per cent of the respondents claimed to depend on family members for care in the event of sickness and poor health. Some 2 per cent chose domestic helpers as the caregivers. About 10 per cent had preferred the street office to take care of them (Respondents are allowed to indicate two choices). Some 42 per cent of them had 
received care from community services and neighbours. Assistance provided included social conversation, visits during festivals, medical consultation and advice, clothe washing, connecting to relatives, care during sickness, meal preparation, and escort service to see doctors (Tianjin Elderly Livelihood Survey Group, 1998).

\section{Guangzhou Wen Chang Street Office}

As the provincial capital of the Guangdong province, Guangzhou, with a population of 6.4 million, is ranked top among cities in China in terms of the total value of industrial output, budgetary revenue among local governments, per capita wages, per capita disposable income, and per capita personal saving.

Among the 8,498 places in homes for the aged in 1997, 33.7 per cent of them were operated by the city and district government, 6.3 per cent by the street offices, and 41.7 per cent by township governments, and 18.3 per cent by private for-profit sector (China Social Work, 4, 1998:11). Guangzhou has a total of 86 street offices with an average population of 40,000 people in each street office. In 1997, these street offices operated a total of 89 community service centres, 49 homes for the aged, 89 work therapy stations, 1,509 service facilities for the elderly, 14,483 service stations for the veterans, 632 service facilities for the disabled, 1,813 volunteer groups with a membership of 114,000 people, and charity trust funds of 13 million yuan (Guangzhou Yearbook Editorial Committee, 1998:376). Primarily, welfare services are catered mainly for the 'three nos' elderly. They would be taken care either in homes for the elderly operated by the government and the street offices. Among the 700 'three nos' elderly persons living in homes for the aged, 130 lived in the homes operated by the street offices. Some 80 per cent of the places in the homes for the aged operated by the street offices are charging fees at market rates.

In 1997, community services received 12 million yuan from the city government 
and 0.5 million yuan from the welfare lottery fund. These allocations were used mainly for capital and facility construction. In addition, community services had made a net profit of 20 million yuan to finance the welfare services.

Wen Chang Street Office has a population of 36,000 people. About 15 per cent of the population are aged over 60 (5,400 people). There were 254 single elderly persons living in the neighbourhood, and only 18 of them were classified as 'three nos’ and received free social welfare services from the government.

For these single elderly, the street office offered two kinds of services. The home for the aged had five residents with poor health. Four of them were the 'three nos' and one was paying fees. A maid from the village was employed to take care of the practical needs of these elderly people, such as escorting them to consult doctors, house cleaning, delivery of meals, and washing clothes. Meals were prepared in the nursery operated by the street office.

For other home bound elderly persons, 'care groups’ would be formed by cadres and volunteers. They would work out an agreement with the elderly persons in need. The group would provide services such as delivery of meals, shopping, escort service for medical consultation, and home visits. The street office has established a team of 2,290 volunteers. They were mainly secondary school students and local residents.

In medical care, the local clinic operated by the street office provided 120 single and poverty-stricken elderly persons with a free medical service (limited to a maximum of 50 yuan a month). For those home bound elderly, medical consultation would be provided at home (family beds). The street office also signed medical care agreements with 170 elderly, and provided them with regular medical check up. The services were provided by 200 students from a nursing school.

The street office has established a charity fund, financed by local donations from 
individuals and companies. About 100 single elderly received a monthly allowance ranging from 30 yuan to 120 yuan from the Foundation. With the support from the fund, a variety of personal services were offered to the elderly persons. They included the installation of alarm bells for the single elderly (connected to the members of the care groups lived nearby). The Charity Foundation also supported mass recreational activities, such as meals at the restaurants and picnics for the single elderly. For the 18 'three nos' elderly, a local company had committed to donate rice and deliver to them regularly.

This case example represents what a comparatively well-off neighbourhood can do to provide assistance to the frail elderly. To be sure, the welfare provisions in the majority of the neighbourhoods in China are still developing.

\section{An Assessment}

Traditionally, Chinese neighbourhood organizations functioned more often as an instrument of the government to publicize laws and policies and exercise social control. In recent years, neighbourhood-based social welfare services have been developed to provide a supportive network for vulnerable population. Indisputably, community service is a unique form of welfare services in China. Yet the quality of provisions is largely dependent on the economic capacity of the neighbourhood government to finance the welfare programmes. Variations in the quality and kinds of welfare services provided by the neighbourhoods can be substantial. Poor neighbourhoods with little revenue-generating capacity would most likely fail to provide adequate welfare services for their residents in needs. Ironically, residents in poor neighbourhoods are presumably have more urgent needs than those in the wealthy neighbourhoods. The community services system in fact tends to exacerbate the existing inequality in the access to social services among urban residents. 
In terms of service priority, the services for the frail elderly persons primarily focus on the 'three nos' and the single elderly. Only the 'three nos' are entitled to receive service free of charge. When children are not available, the neighbourhood organizations would become an important source of help for the elderly. In this way, there is hardly any service supporting family caregivers. In some other neighbourhoods, there may be day care centres for the elderly and limited home help. These services are often fee-charging. For those families with adequate income, they can often employ live-in domestic helpers, often from the villages, with a monthly salary of US\$40-50. For those elderly persons in low-income families, the task of providing care to the frail and homebound elderly persons can be economically, physically and psychologically very demanding. In another study of family care of the elderly in Guangzhou, it was found that family members, with no formal service support, had to shoulder a stressful and demanding responsibility to provide adequate care to dementia elderly parents (Leung, 1999b).

Finally, it is evident that the Chinese government cannot take for granted that family care is unlimited, open-ended and continuous. It is also evident that the effectiveness and reliability of enforcing family care obligations through coercive legal action and moral appeal is in doubt. Without proper and adequate support from social services, the capacity of the family caregivers can deteriorate rapidly. Hopefully, we would like to see the professionalization and institutionalization of the community-based welfare services supporting family caregivers in the coming years.

\section{References}

Beijing Review. Beijing.

China Civil Affairs. Beijing: Ministry of Civil Affairs. 
China Research Centre on Aging. (1994) A Data Compilation of the Survey on China's Support Systems for the Elderly. Beijing: Hua Ling Press.

China Social Work. Beijing: Ministry of Civil Affairs.

Guangzhou Yearkbook Editorial Committee. (1998) Guangzhou Yearbook 1998. Beijing: State Statistical Publishers.

Leung, J. (1994a) 'Dismantling the Iron Rice Bowl: Welfare Reforms in the PRC”, Journal of Social Policy 23 (3): 341-361.

Leung, J. (1994b) 'The Development of Social Work Education in China: Issues and Prospects”, Asia Pacific Journal of Social Work, 4 (2): 209-223.

Leung, J. and R. Nann (1995) Authority and Benevolence: Social Welfare in China. New York: St. Martins Press.

Leung, J. (1996) 'The Emergence of Unemployment Insurance in China: Problems and Issues’, Canadian Journal of Social Policy Review 38:5-17.

Leung, J. (1997) 'Family Support for the Elderly in China: Issues and Challenges', Journal of Aging and Social Policy 9 (3): 7-101.

Leung, J. (1998) 'Social Security Reforms: The Long and Winding Road', in J. Cheng (ed) China Review 1998, pp.479-99. Hong Kong: The Chinese University Press.

Leung, J. (1999a). 'The Emergence of a Community-based Social Assistance Programme in Urban China', Social Policy and Administration 33 (1):39-54.

Leung, J. (1999b). 'An Appraisal of the Family Caregiving Functions for Elderly Persons Receiving the Portable Comprehensive Social Security Assistance in Hong Kong', Conference Proceedings, Asia-Pacific Regional Conference for the International Year of Older Persons, April 26-29, 1999, Hong Kong, pp.38-45.

Shi, Z. X. and Y. Zhu (1998) China Social Welfare and Social Progress Report (1998). Beijing: Social Science Publishers. 
Community-based Service in China

State Statistical Bureau (1995, 1998) China Statistical Yearbook 1998. Beijing: China Statistical Publishers.

State Statistical Bureau (1997) China Population Statistics Yearbook 1997. Beijing: China Statistical Publishers.

Tianjin Elderly Livelihood Survey Group (1998) 'The Dependency of the Livelihood of Urban Elderly on Family and Community’, China Social Work 3:27-29.

World Bank (1997) Old Age Security: Pension Reform in China. Washington, DC: The World Bank. 